\title{
sciendo
}

\section{Repeated Sprint Ability in Youth Soccer Players: Independent and Combined Effects of Relative Age and Biological Maturity}

\author{
by \\ João P. Duarte1,2,3, Manuel J. Coelho-e-Silva1,2, Daniela Costa1,2, \\ Diogo Martinho ${ }^{1,2,4}$, Leonardo G. O. Luz ${ }^{2,5}$, Ricardo Rebelo-Gonçalves², \\ João Valente-dos-Santos $2,6,7,8$, António Figueiredo ${ }^{1,2}$, André Seabra ${ }^{9}$, \\ Robert M. Malina ${ }^{10}$
}

The objective of the study was to examine the effects of the relative age effect (RAE) and predicted maturity status on body size and repeated sprint ability (RSA: $7 \times 34.2 \mathrm{~m} / 25 \mathrm{~s}$ interval) in youth soccer. The sample was composed of 197 male players aged 13-14 years. Body mass, stature, and sitting height were measured, RSA was assessed in the field, and age at peak height velocity (APHV) was predicted. Factorial ANOVA tested the independent and combined effects of $R A E$ given by birth quarters $(B Q s)$ and maturity status on dependent variables. Players born in the second birth quarter $(B Q 2)$ were significantly taller $(F=4.28, p<0.01)$ than their peers born in $B Q 1$ and $B Q 3$. Additionally, players born in $B Q 2$ performed better than players born in BQ4 in RSA total time and ideal time ( $F$ ranged between 4.81 and $4.90, p<0.01)$, while players born in $B Q 1$ exhibited a lower RSA fatigue index compared to those born in $B Q 4(F=2.90, p<0.05)$. The interaction of the $B Q$ and maturity status was a significant source of interindividual variation for body size ( $F$ ranged between 64.92 and 105.57; $p<0.01$ ) and RSA output ( $F$ ranged between 4.082 and $6.76 ; p<0.05)$. In summary, being relatively older and, simultaneously, advanced in maturity status corresponds to a substantial advantage in characteristics that are related to soccer-specific fitness.

Key words: youth sports, growth, peak height velocity.

\section{Introduction}

The relative age effect (RAE) refers to the over-representation of players born in the earliest quarter or trimester of the calendar and/or selection year, and is reasonably well established in youth soccer (Deprez et al., 2012; Gil et al., 2014; Helsen et al., 2012; Wattie et al., 2015). The RAE reflects a bias associated with the birth month and corresponds to a substantial difference between observed and expected distributions of soccer players by the birth month (Gil et al., 2014; Helsen et al., 1998). A significantly higher proportion of soccer players from youth to professional levels are born in the first quarter of the birth year, e.g., participants in the 1990 World Cup, 1989 U-17

1 - Faculty of Sport Sciences and Physical Education, University of Coimbra, Coimbra, Portugal.

2 - CIDAF (uid/dtp/04213/2019), University of Coimbra, Coimbra, Portugal.

3 - Portuguese Foundation for Science and Technology (SFRH/BD/101083/2014), Lisbon, Portugal.

4 - Portuguese Foundation for Science and Technology (SFRH/BD/121441/2016), Lisbon, Portugal.

5 - LACAPS, Federal University of Alagoas (UFAL), Arapiraca, Brazil.

6 - Portuguese Foundation for Science and Technology (SFRH/BPD/100470/2014), Lisbon, Portugal.

7 - Institute for Biomedical Imaging and Life Sciences (IBILI), University of Coimbra, Coimbra, Portugal.

8 - Faculty of Physical Education and Sport, Lusófona University of Humanities and Technologies, Lisbon, Portugal.

9 - CIAFEL, University of Porto, Porto, Portugal.

10 - Department of Kinesiology and Health Education, University of Texas, Austin, USA. 
and U20 World Championships (Barnsley et al., 1992), professional and youth Belgian players (Helsen et al., 1998), senior semi-professional and amateur Belgian players (Vaeyens et al., 2004), U17 players at regional camps (Glamser and Vincent, 2004), among others. It is also suggested that the RAE is more strongly apparent at higher levels of involvement in youth soccer (Mujika et al., 2009). The phenomenon was clearly apparent when the Belgian Soccer Federation adopted January 1st as the start of the selection year following the guidelines of the International Football Association (Helsen et al., 2000). Previously to 1997, August 1st was the earliest day for grouping soccer players. This shift affected birth-month distributions throughout youth soccer categories (10-12, 12-14, 14-16, and 16-18 years) for 1996-1997 compared to the 19971998 competitive seasons. Youth players born during the early part of the new selection calendar (January to March) were more likely to be identified as "talented" and to be exposed to higher levels of coaching, in contrast to players born in the latest quarter (August to October) who were less likely to be identified as "talented". The month of birth is indicated as a potential constraint for long-term success in several sports, and a more comprehensive approach for understanding the RAE phenomenon has been recommended (Wattie and Baker, 2013; Wattie et al., 2015). An issue often overlooked in studies of the RAE is the time of observation. Earlier studies (Deprez et al., 2013; Gil et al., 2014) considered study designs that included several observations during the calendar year. Deprez et al. (2013), for example, assessed 374 soccer players, 10.6-16.6 years, on 15 occasions randomly distributed over five years (555 data points) and subsequently compared the players by birth quarters within 2year age groups. Gil et al. (2014) examined 88 youth players between March and April and subsequently compared by birth quarter (BQ) groups defined by quartiles of chronological age (CA). Critical interpretations regarding the influence of the RAE on variables of interest require players of the same CA measured at the same time of the year. Such data are generally lacking.

A recent study examined the birth dates of 222 male participants of the U-9 Euro Championship Soccer Tournament in Vienna in
2016 and demonstrated that the selection process was associated with the biological maturity status and the RAE (Muller et al., 2018). The prepubertal players were divided into groups of maturity based on estimated age at peak height velocity (APHV) and a significant difference was found between the distribution of early, normal and late maturing groups and distribution by birth quarters. The previous results should be interpreted cautiously given limitations of the prediction equations time before APHV termed maturity offset (Mirwald et al., 2002; Moore et al., 2015). Validation studies consistently demonstrated that predicted APHV tended to increase with CA at prediction and, in parallel, overestimated APHV in early maturing children and adolescents, and underestimated APHV in late maturing participants (Koziel and Malina, 2018; Malina and Koziel, 2014; Malina et al., 2016). By inference, reported differences in predicted APHV in U-9 soccer players according to the BQ likely reflected the variation of the predictions associated to CA. Moreover, the validation study with Polish children and adolescents followed annually concluded that the application of the maturity-offset algorithm was reasonably for the age of 13 and 14 (Malina and Koziel, 2014). Meantime, differences between players of contrasting maturity status were marked in midadolescence, but were attenuated in late adolescence. Moreover, inter-individual variability in body size, functional capacities and sport-specific skills in soccer players 11-12 and 1314 years old is considerable (Figueiredo et al., 2009b). Also, biological maturity status is an additional and significant determinant of success (Figueiredo et al., 2009b) and selection in soccer at these ages (Coelho-e-Silva et al., 2010). Studies of youth soccer players provide relatively limited data addressing the potential influence of the RAE and maturity-related variation on performance.

Repeated high-speed actions correspond to an essential physical component in soccer matches (Buchheit et al., 2010). It is considered a complex fitness trait that is apparently related to neuromuscular (Bucheit et al., 2012) and metabolic factors (Girard et al., 2010). In youth soccer, a previous study extracted from Coimbra Longitudinal Soccer Study compared the characteristics of 114 Portuguese U-14 players by their competitive level and concluded that 
selected players tended to be advanced in terms of skeletal maturity status and, additionally, were heavier, taller, more ego oriented, performed better on the explosive power, repeated sprints and ball control tests (Coelho-e-Silva et al., 2010). The moderate relationship between repeated sprint ability (RSA) and several field and laboratory aerobic and anaerobic tests was noted in 45 adolescent soccer players (RodríguezFernandez et al., 2017) and, among the practical applications of the study, authors suggested heart rate recovery in parallel to RSA output (best sprint, mean time, decrement score) should be systematically considered in the assessment of physical conditioning status. As such, RSA is commonly reported in the evaluation of youth soccer players (Figueiredo et al., 2009a, 2009b; Valente-dos-Santos et al., 2012a). Significant predictors of RSA in a mixed-longitudinal sample of soccer players (11-13 years at baseline and assessed over five years) were CA, skeletal maturity status, body size, estimated fat-free mass, aerobic fitness, lower limb explosive strength and annual volume of training (Valentedos-Santos et al., 2012b).

Assuming RAE and biological maturation as two constraints for success in youth soccer, the present study was aimed to address some of the limitations noted in previous studies. The purpose of this paper was to examine the influence of RAE and estimated biological maturity status on body size and RSA in youth soccer players within a single competitive age category (U-15) who were measured in the last month of the year (2015). It was hypothesized that players who were born in the first half of the year and were advanced in biological maturity status would have substantial size-associated advantages and would perform better in RSA considered a crucial characteristic in youth soccer regarding physical conditioning programs and also in the sports selection.

\section{Methods}

\section{Participants}

The sample included 197 (age $=14.1 \pm 0.6$ years; stature $=168.6 \pm 6.6 \mathrm{~cm}$; body mass $=59.5 \pm$ $8.4 \mathrm{~kg}$ ) male club level soccer players meeting the following inclusion criteria: (i) measurement performed in the last month of the year; (ii) U-15 age category, (iii) participation in competitive youth soccer at the national level; and (iv) a minimum of two completed competitive seasons in the sport. Information on training experience in the sport and playing position was obtained from the coaches of the respective players. Players were categorized into one of six individual playing positions in accordance with previous research (Carling, 2010): goalkeepers $(\mathrm{n}=23)$, full-backs ( $\mathrm{n}$ $=36)$, central defenders $(n=36)$, wide midfielders $(n=32)$, central midfielders $(n=32)$ and centreforwards $(n=34)$. All players were of European ancestry and were classified as initiates (U-15) according to the structure of the Portuguese Soccer Federation. After explaining the scope of the study, written informed consent was obtained from both players and parents or legal guardians. Participation was voluntary and players were informed that they could discontinue at any time. The study was conducted in accordance with the ethical procedures of the Declaration of Helsinki for human studies by the World Medical Association (General Assembly of the World Medical Association, 2014) and was approved by the Scientific Committee of the University of Coimbra.

\section{Procedures}

Assessments were performed on two separate occasions over a period of two weeks. All players were assessed within a single month (December). Each player was free from injury and had been familiarized with the field test during the week previous to testing. Participants were instructed not to drink coffee or beverages containing caffeine for at least $8 \mathrm{~h}$ before each testing session. All players wore their usual training attire during the data collection. The sequence of tests was selected based on previously outlined recommendations, with players having anthropometric measures (stature, sitting height, and body mass) taken in a rested state followed by the RSA test (Valente-dosSantos et al., 2012b). RSA testing was performed on the same weekday and at the same time period (i.e., 16:00-19:00), under similar outdoor conditions in flat artificial turf controlling for temperature and humidity (Oregon Scientific RMR383HG: air temperature $13.1-18.8^{\circ} \mathrm{C}$; humidity $82-88 \%$ ) after a standardized $10-\mathrm{min}$ warm-up (5-min run and dynamic stretching). All participants were categorized into four BQs according to their month of birth: BQ1: JanuaryMarch; BQ2: April-June; BQ3: July-September; 
BQ4: October-December). Chronological age was the difference between the birth date and the observation day.

\section{Anthropometry}

A single experienced observer performed all measurements following standardized procedures (Lohman et al., 1988). Stature and sitting height were measured to the nearest 0.1 $\mathrm{cm}$ using a stadiometer (Harpenden 98.603, Holtain Ltd, Croswell, UK) and a sitting height table (a Harpenden sitting height table, model 98.607, Holtain Ltd, Crosswell, UK), respectively. Leg length was estimated as stature minus sitting height. Body mass was measured to the nearest $0.1 \mathrm{~kg}$ using a portable scale (SECA model 770, Hanover, MD, USA). Intra-observer technical errors of measurement $\left(\sigma_{\mathrm{e}}\right)$ for anthropometrics were previously reported (Valente-dos-Santos et al., 2012b): stature (0.47), sitting height (0.27) and body mass (0.31).

\section{Biological maturity status}

The APHV was estimated with a sexspecific equation ( $\mathrm{SEE}=0.592,95 \% \mathrm{CI} 1.18$ years) developed on Canadian and Belgian boys (Mirwald et al., 2002). The equation predicts maturity offset (time before or after PHV); CA minus offset provides predicted APHV (estimated time of the maximum rate of growth in stature during the adolescent spurt). Results of two validation studies suggest that the equation may be applicable close to the time of observed PHV in average maturing boys, approximately 13 through 14 years old (Malina and Koziel, 2014; Malina et al., 2016). The sample was divided into three groups according to percentiles for the sample: APHV $<$ P33\% (early maturing), P33\% < APHV < P66\% (average maturing), P66\% < APHV (late maturing).

Repeated sprint ability ( $7 \times 34.2 \mathrm{~m} / 25 \mathrm{~s}$ recovery)

A soccer-specific RSA test known as the Bangsbo Sprint Test (Bangsbo et al., 1991; Kaplan, 2010) was used (Figure 1). The protocol included seven successive $34.2 \mathrm{~m}$ maximal sprints (including a slalom). The player was positioned behind the starting line with the lead foot $0.3-\mathrm{m}$ behind the line. Following each sprint, there was a period of active recovery consisting of jogging (25 $\mathrm{s}$ to cover the distance of $40 \mathrm{~m}$ back to the starting line). Verbal feedback was given at the $5^{\text {th }}, 10^{\text {th }}$, $15^{\text {th }}$, and $20^{\text {th }} \mathrm{s}$ across the recovery period. Subsequent sprints were initiated after the end of the recovery interval with players positioning again the lead foot $0.3 \mathrm{~m}$ behind the starting line. The time for each sprint was recorded to the $0.01 \mathrm{~s}$ with a digital chronometer connected to photoelectric cells (Globus Ergo Timer Timing System, Codogné, Italy). A pair of photocells was positioned along the starting line and another pair was positioned on the finish line, $0.8 \mathrm{~m}$ above the floor. Several indicators of sprinting ability were considered: the best sprint time (which usually occurs in the first or second trial), mean sprint time (average time of seven sprints), total sprint time (sum of 7 sprints) and ideal sprint time (best sprint multiplied by seven) (Valente-dos-Santos et al., 2012b). A decrement score (\%) among the seven sprints relative to the ideal time was also calculated as [(mean sprint time/best sprint time $\times$ 100) - 100] (Bishop et al., 2001; Valente-dos-Santos et al., 2012a). The best sprint of the familiarization session was retained and participants who failed to achieve at least $95 \%$ of the time of the sprint in the first run in the final testing session were excluded in order to avoid pacing during the test (Bishop et al., 2001). All players met the inclusion criteria. Coefficients of reliability for replicate tests of 32 players within 1 week were 0.86 for ideal time and 0.91 for total time (Valente-dos-Santos et al., 2012b).

\section{Statistical analysis}

Descriptive statistics were calculated for the total sample [frequencies; mean \pm standard deviation (SD)], by birth quarters and categories of estimated biological maturity status. The association between the $\mathrm{BQ}$ and biological maturity status distribution was investigated with the chi-square statistic. Analysis of variance (ANOVA) was used to test the effect of the birth quarter (BQ1, BQ2, BQ3, BQ4) and biological maturity status (earliest, average, latest maturing) on CA, years of training, body size, and RSA output. Factorial ANOVA was used to test the interaction term of birth quarters and maturity status on the dependent variables. Magnitude effect size was estimated using the "effect size correlation" (ES-r), derived from the square root of the ratio of the F-value squared and the difference between the F-value squared and degrees of freedom (Rosnow and Rosenthal, 1996). The estimate provides a measure of effectmagnitude within the traditional statistical framework. Coefficients were interpreted as 
follows (Hopkins et al., 2009): trivial $(<0.1)$, small (0.1 to 0.3 ) moderate (0.3 to 0.5$)$, large (0.5 to 0.7 ), very large $(0.7$ to 0.9$)$, nearly perfect $(>0.9)$. All statistical analyses were performed using SPSS for MAC OS X (version 21.0).

\section{Results}

Descriptive statistics of participants by BQ and maturity status are presented in Tables 1 and 2. There is a decreasing number of players from BQ1 to BQ4 (BQ1: 29.4\%; BQ2: 27.4\%; BQ3: 25.9\%; BQ4: $17.3 \%$ ), and a significant association between the $B Q$ and maturity status $\left(\chi^{2}=13.016, p<0.05\right)$. $\mathrm{BQ} 2$ has proportionally more early maturing players than the other three birth quarters.

Table 3 examines the effect of $B Q$ on the variables of interest. Players in the respective birth quarters differed significantly in body size and RSA output. Players in $\mathrm{BQ} 2$ were taller $(\mathrm{F}=4.28, p$ $<0.05$; ES-r $=0.25$ ) than players from BQ3 and $B Q 4$. Players from $B Q 2$ were also significantly faster than players in BQ4 in RSA best sprint, mean time, total time and ideal time $(\mathrm{F}>4.0, p<$ 0.05 ; ES- $r=0.27$ ). Players in BQ1 exhibited a lower RSA decrement score compared to BQ4 $(\mathrm{F}=3.16, p$ $<0.05$; ES-r $=0.22$ ). Variation among maturity groups showed the expected gradient for body size (Table 4), i.e., early $>$ average $>$ late $(F=84.67$ to $163.34 ; p<0.05$; ES-r $=0.69$ to 0.80 ). Differences were not statistically significant for RSA output. Average maturing players presented a lower RSA decrement score compared to early and late maturing players $(\mathrm{F}=6.87, p<0.01$; $\mathrm{ES}-\mathrm{r}=0.26)$.

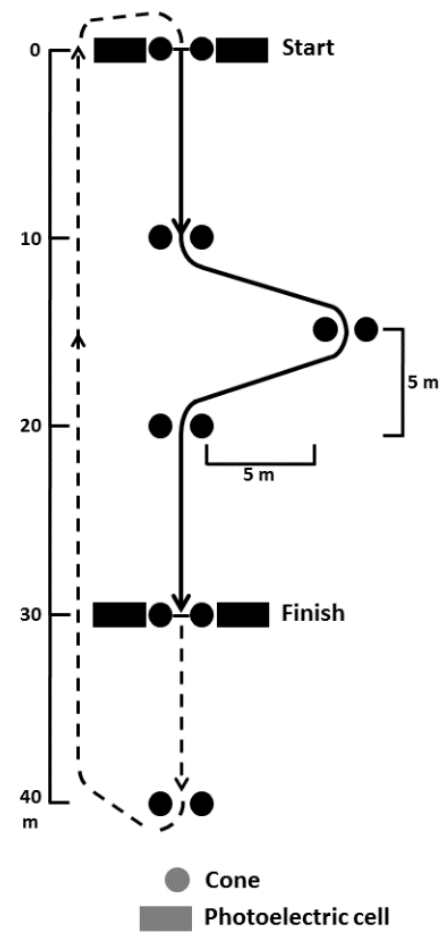

Figure 1

Course of the repeated-sprint ability test (Bangsbo Sprint Test) 
Table 1

Descriptive characteristics (frequencies; mean \pm standard deviation) of adolescent soccer players aged 13-14 years $(n=197)$ by birth quarter

\begin{tabular}{lccccccc}
\hline & \multicolumn{9}{c}{ Birth quarters } & & \\
\cline { 2 - 5 } Variables & BQ1 & BQ2 & BQ3 & BQ4 & $\chi^{2}$ & d & $p$ \\
& $(n=58)$ & $(n=54)$ & $(n=51)$ & $(n=34)$ & & $f$ &
\end{tabular}

Maturity status, $\mathrm{f}(\%)$

\begin{tabular}{|c|c|c|c|c|c|c|}
\hline Early & $12(6.1)$ & $24(12.2)$ & $17(8.6)$ & $12(6.1)$ & 13.02 & 6 \\
\hline Average & $28(14.2)$ & $17(8.6)$ & $12(6.1)$ & $12(6.1)$ & & \\
\hline Late & $18(9.1)$ & $13(6.6)$ & $22(11.2)$ & $10(5.1)$ & & \\
\hline
\end{tabular}

$\begin{array}{lcccc}\text { Chronological age, years } & 14.21 \pm 0.50 & 14.43 \pm 0.51 & 13.66 \pm 0.55 & 13.93 \pm 0.52 \\ \text { Predicted APHV, years } & 14.35 \pm 0.53 & 14.15 \pm 0.56 & 14.36 \pm 0.64 & 14.14 \pm 0.49 \\ \text { Training experience, years } & 4.90 \pm 1.28 & 5.10 \pm 1.11 & 4.78 \pm 1.46 & 4.29 \pm 1.62 \\ & & & & \\ \text { Stature, cm } & 161.9 \pm 8.0 & 165.5 \pm 9.5 & 159.8 \pm 8.6 & 160.4 \pm 8.8 \\ \text { Sitting height, cm } & 82.9 \pm 4.7 & 84.3 \pm 4.9 & 81.4 \pm 5.0 & 81.8 \pm 4.7 \\ \text { Body mass, kg } & 51.6 \pm 7.7 & 54.2 \pm 9.6 & 49.1 \pm 10.7 & 50.7 \pm 9.8 \\ & & & & \\ \text { RSA best sprint, s } & 7.87 \pm 0.39 & 7.68 \pm 0.33 & 7.80 \pm 0.33 & 7.95 \pm 0.43 \\ \text { RSA mean time, s } & 8.12 \pm 0.42 & 7.96 \pm 0.38 & 8.10 \pm 0.38 & 8.28 \pm 0.48 \\ \text { RSA sum of 7 sprints, s } & 56.86 \pm 2.98 & 55.64 \pm 2.62 & 56.70 \pm 2.68 & 58.00 \pm 3.41 \\ \text { RSA ideal time, s } & 55.08 \pm 2.79 & 53.68 \pm 2.35 & 54.59 \pm 2.33 & 55.60 \pm 3.04 \\ \text { Decrement score, \% } & 3.21 \pm 1.29 & 3.65 \pm 1.93 & 3.88 \pm 1.91 & 4.30 \pm 1.68\end{array}$

$f=$ frequencies; $A P H V=$ age at peak height velocity; $R S A=$ repeated sprint ability; $B Q 1$

= birth quarter 1 (January-March); BQ2 = birth quarter 2 (April-June); $B Q 3=$ birth quarter 3 (July-September); $B Q 4=$ birth quarter 4 (October-December) 
Table 2

Descriptive characteristics (mean \pm standard deviation) of adolescent soccer players aged 13-14 years $(n=197)$ by maturity status using tertiles of estimated APHV

\begin{tabular}{|c|c|c|c|}
\hline \multirow[b]{3}{*}{ Variables } & \multicolumn{3}{|c|}{ Maturity status (APHV) } \\
\hline & $\begin{array}{l}<\text { Percentil 33\% } \\
\quad(\mathrm{n}=65)\end{array}$ & $\begin{array}{l}\text { Percentiles: } 33 \% \text { to } 66 \% \\
\qquad(n=69)\end{array}$ & $\begin{array}{l}>\text { Percentil } 66 \% \\
\quad(\mathrm{n}=63)\end{array}$ \\
\hline & & & \\
\hline Chronological age, years & $14.12 \pm 0.58$ & $14.12 \pm 0.58$ & $14.00 \pm 0.55$ \\
\hline Predicted APHV, years & $13.65 \pm 0.23$ & $14.23 \pm 0.14$ & $14.93 \pm 0.33$ \\
\hline Training experience, years & $5.10 \pm 1.44$ & $4.67 \pm 1.39$ & $4.72 \pm 1.26$ \\
\hline Stature, $\mathrm{cm}$ & $168.6 \pm 6.6$ & $163.2 \pm 6.3$ & $153.7 \pm 6.3$ \\
\hline Sitting height, $\mathrm{cm}$ & $87.2 \pm 2.7$ & $83.1 \pm 2.8$ & $77.4 \pm 3.5$ \\
\hline Body mass, $\mathrm{kg}$ & $59.5 \pm 8.4$ & $51.4 \pm 5.8$ & $43.2 \pm 6.4$ \\
\hline RSA best sprint, $\mathrm{s}$ & $7.74 \pm 0.40$ & $7.82 \pm 0.38$ & $7.88 \pm 0.34$ \\
\hline RSA mean time, $\mathrm{s}$ & $8.04 \pm 0.47$ & $8.06 \pm 0.40$ & $8.20 \pm 0.37$ \\
\hline RSA sum of 7 sprints, $\mathrm{s}$ & $56.28 \pm 3.34$ & $56.42 \pm 2.83$ & $57.39 \pm 2.62$ \\
\hline RSA ideal time, $\mathrm{s}$ & $54.08 \pm 2.88$ & $54.73 \pm 2.67$ & $55.18 \pm 2.38$ \\
\hline Decrement score, $\%$ & $4.02 \pm 1.95$ & $3.08 \pm 1.43$ & $4.03 \pm 1.68$ \\
\hline
\end{tabular}

$A P H V=$ age at peak height velocity; $R S A=$ repeated sprint ability 
Table 3

Results of ANOVA to examine the effect of birth quarter

\begin{tabular}{|c|c|c|c|c|c|}
\hline \multirow[b]{2}{*}{ Variables } & \multicolumn{2}{|c|}{ ANOVA } & \multicolumn{2}{|c|}{ Effect size } & \multirow{2}{*}{$\begin{array}{l}\text { Post-hoc pairwise } \\
\text { comparisons }\end{array}$} \\
\hline & F-value & $p$ & ES-r & Magnitude & \\
\hline Predicted APHV & 1.92 & 0.13 & 0.17 & small & \\
\hline Training experience & 2.49 & 0.06 & 0.20 & small & \\
\hline Stature & 4.28 & 0.01 & 0.25 & small & $\mathrm{BQ} 2>\mathrm{BQ} 3 \& \mathrm{BQ} 4$ \\
\hline Sitting height & 83.60 & 0.02 & 0.23 & small & $\mathrm{BQ} 2>\mathrm{BQ} 3$ \\
\hline Body mass & 2.54 & 0.06 & 0.18 & small & $\mathrm{BQ} 2>\mathrm{BQ} 3$ \\
\hline RSA best sprint, $\mathrm{s}$ & 4.31 & $<0.01$ & 0.25 & small & $\mathrm{BQ} 2<\mathrm{BQ} 4$ \\
\hline RSA mean time, $\mathrm{s}$ & 4.28 & $<0.01$ & 0.25 & small & $\mathrm{BQ} 2<\mathrm{BQ} 4$ \\
\hline RSA sum of 7 sprints, s & 4.77 & $<0.01$ & 0.26 & small & $\mathrm{BQ} 2<\mathrm{BQ} 4$ \\
\hline RSA ideal time, $\mathrm{s}$ & 4.53 & $<0.01$ & 0.28 & small & $\mathrm{BQ} 2<\mathrm{BQ} 4$ \\
\hline Decrement score, $\%$ & 3.16 & 0.03 & 0.22 & small & $\mathrm{BQ} 1<\mathrm{BQ} 4$ \\
\hline
\end{tabular}

$A P H V=$ age at peak height velocity; $R S A=$ repeated sprint ability; $E S-r=$ effect size correlation; $B Q 1=$ birth quarter 1 (January-March); BQ2 = birth quarter 2 (AprilJune); $B Q 3=$ birth quarter 3 (July-September); $B Q 4=$ birth quarter 4 (October-

December) 
Table 4

Results of ANOVA to examine the effect of maturity status using tertiles of predicted

\begin{tabular}{|c|c|c|c|c|c|}
\hline \multirow[b]{3}{*}{ Variables } & \multicolumn{4}{|c|}{ APHV } & \multirow{3}{*}{$\begin{array}{l}\text { Post-hoc } \\
\text { pairwise } \\
\text { comparisons }\end{array}$} \\
\hline & \multicolumn{2}{|c|}{ ANOVA } & \multicolumn{2}{|c|}{ Effect size } & \\
\hline & F-value & $p$ & ES-r & $\begin{array}{l}\text { Magnitud } \\
\text { e }\end{array}$ & \\
\hline Training experience & 1.60 & 0.20 & 0.13 & small & \\
\hline Stature & 85.40 & $<0.01$ & 0.69 & large & $\mathrm{G} 1>\mathrm{G} 2>\mathrm{G} 3$ \\
\hline Sitting height & 163.34 & $<0.01$ & 0.80 & very large & $\mathrm{G} 1>\mathrm{G} 2>\mathrm{G} 3$ \\
\hline Body mass & 84.67 & $<0.01$ & 0.69 & large & $\mathrm{G} 1>\mathrm{G} 2>\mathrm{G} 3$ \\
\hline RSA best sprint, $\mathrm{s}$ & 2.24 & 0.11 & 0.15 & small & \\
\hline RSA mean time, $\mathrm{s}$ & 3.01 & 0.05 & 0.17 & small & \\
\hline RSA sum of 7 sprints, s & 2.72 & 0.07 & 0.17 & small & \\
\hline RSA ideal time, s & 2.75 & 0.07 & 0.17 & small & \\
\hline Decrement score, $\%$ & 6.87 & $<0.01$ & 0.26 & small & $\mathrm{G} 2<\mathrm{G} 1 \& \mathrm{G} 3$ \\
\hline
\end{tabular}

$A P H V=$ age at peak height velocity; $R S A=$ repeated sprint ability; $E S-r=$ effect size correlation; $G 1=$ earliest $(p<33 \%) ; G 2=$ on time $(P 33-66 \%) ; G 3=$ Latest $(p>66 \%)$

Table 5

Results of ANOVA to examine the effect of the interaction term (birth quarter $\times$ maturity status)

\begin{tabular}{|c|c|c|c|c|}
\hline \multirow[b]{2}{*}{ Variables } & \multicolumn{2}{|c|}{ ANOVA } & \multicolumn{2}{|c|}{ Effect size } \\
\hline & F-value & $p$ & ES-r & Magnitude \\
\hline Training experience & 6.41 & 0.01 & 0.18 & small \\
\hline Stature & 64.92 & $<0.01$ & 0.51 & large \\
\hline Sitting height & 105.57 & $<0.01$ & 0.60 & large \\
\hline Body mass & 66.93 & $<0.01$ & 0.51 & large \\
\hline RSA best sprint, s & 2.41 & $<0.01$ & 0.35 & moderate \\
\hline RSA mean time, $s$ & 2.57 & $<0.01$ & 0.36 & moderate \\
\hline RSA sum of 7 sprints, $s$ & 2.70 & $<0.01$ & 0.37 & moderate \\
\hline RSA ideal time, $\mathrm{s}$ & 2.57 & $<0.01$ & 0.36 & moderate \\
\hline Decrement score, \% & 2.72 & $<0.01$ & 0.37 & moderate \\
\hline
\end{tabular}

$R S A=$ repeated sprint ability; $E S-r=$ effect size correlation 
Results of the factorial ANOVA to test the interaction term of birth quarters and maturity status on the dependent variables are given in Table 5. The interaction between the $\mathrm{BQ}$ and biological maturity status was a consistent source of variation in body size ( $\mathrm{F}=64.92$ to $105.57 ; p<$ 0.05 ; ES-r $=0.51$ to 0.60$)$ and RSA output $(\mathrm{F}=2.41$ to $2.72 ; p<0.01$; ES-r $=0.35$ to 0.37 ).

\section{Discussion}

The present study evaluated the independent and combined effects of the RAE, defined by the $B Q$, and biological maturity status, defined by tertiles of predicted APHV, on body size and RSA output in U-15 soccer players. This age group ordinarily marks the beginning of fullside, i.e., $11 \times 11$, competitive soccer (Coelho-eSilva et al., 2010); at earlier ages, competitions are based on $7 \times 7$ (Sanchez-Sanchez et al., 2018). This competitive age group was selected to approximate the CA interval during which PHV occurs, on average, 13.0 to 14.9 years; PHV occurs, on average, about $14.0 \pm 1.1$ years (Malina and Koziel, 2014). Estimated APHV based on longitudinal samples of youth soccer players is limited to three series. Two series involved Welsh $(n=32)$ and Danish $(n=8)$ boys regularly active in soccer although the levels of competition and intensity of training were not indicated (Bell, 1993; Froberg et al., 1991). Mean APHV were identical in both studies, $14.2 \pm 0.9$ years. The third series included Belgian club players $(n=33)$ who had a mean APHV of $13.8 \pm 0.8$ years (Philippaerts et al., 2006). The estimated APHV for the three samples approximate the age range of the players comprising the present study ( $14.3 \pm 0.6$ years).

The majority of players in the current sample $(57 \%)$ were born in the first half of the year (BQ1 and BQ2), consistent with the hypothesis of the study and with the RAE literature for youth soccer (Wattie et al., 2015). For example, the youngest third of a single CA group of youth players in English training centers included only $11 \%$ of the player pool (Simmons and Paull, 2001). Results of the present analysis also highlight the interaction of RAE and maturity status as potential developmental constraints among adolescent soccer players. The interaction of RAE and maturity status yielded a large effect, specifically on body size. Players born earlier in the birth year and classified as early maturing were taller and heavier compared to their peers born later and classified as late maturing. The interaction effect was moderate for running speed assessed as RSA.

Among 133 Portuguese U-15 soccer players (14.3 \pm 0.6 years), performances on several short-term maximal intensity tests, including the $10 \mathrm{~m}$ and $30 \mathrm{~m}$ dashes varied significantly by birth semesters; the differences, however, were attenuated when skeletal age (Tanner-Whitehouse 3 method) was statistically controlled (Fragoso et al., 2015). Unfortunately, the age range of the sample was not indicated and the difference between skeletal and CA was not considered. Previous longitudinal studies with regional level Portuguese soccer players have highlighted that total RSA time improved progressively from ages 11 to 17 years (Valente-dos-Santos et al., 2012a, $2012 b$ ); performance also varied with skeletal maturity status and followed a gradient early $>$ on time $>$ late. This observation is consistent with maturity-associated changes in body size, static and functional strength, power and running speed of youth soccer players (Figueiredo et al., 2009b; Malina et al., 2000). The apparent independent effect of CA and skeletal maturity status contrasted observations from crosssectional studies that emphasized that performance in RSA improves during maturation of highly trained youth soccer players, although a plateau occurs from 15 years of age (Mujika et al., 2009). Differences in observations may reflect individual differences in the timing of adolescent spurts in body size, running speed and power (Malina et al., 2004). It is also reasonable to hypothesize an interaction between RAE and skeletal maturity status that influences performances among adolescent players.

The results suggest a need for an interactive heuristic approach in studies of the RAE in youth soccer and other sports, and a need to extend such an approach to different age groups. The RAE is a social construct associated with the interactions of pressures asserted by developmental and social constraints (Horn and Okumura, 2011). Developmental pressures are associated with individual differences in growth, maturation and behavioral development per se and their interactions with sports environments. Social constraints of interest relate to the sports environment, i.e., the ongoing search for talent, 
selection practices associated with physical attributes rather than soccer skills, an excessively competitive culture, and so on.

The present study has both limitations and strengths. An established indicator of biological maturity status was not available for the players. Predicted APHV based on the equation of Mirwald et al. (2002) was used as the maturity indicator. Players were classified as early, average or late maturing using tertiles of predicted ages at PHV for the total sample. Other studies of soccer players have used only two groups, for example, early (predicted age at PHV $<\mathrm{P} 50 \%$ ) and late (predicted age at PHV > P50\%) maturing players in modeling developmental changes in the Yo-Yo intermittent recovery test (Deprez et al., 2014). As noted, validation studies in longitudinal samples of Polish and American youth (Koziel and Malina, 2018; Malina and Koziel, 2014; Malina et al., 2016) indicated limitations of the prediction equation. Predictions were dependent upon CA and probably body size at the time of prediction, had a reduced range of variation, and had limitations with early and late maturing boys defined by observed ages at PHV. A strength of the current study was its design that focused on a single competitive group, i.e., U-15. All measurements were taken in the month of December of the year when all players attained their 13th and 14th birthdays. This contrasts other studies that did not indicate the interval or time period over which measurements were obtained (Deprez et al., 2013; Gil et al., 2014; Sherar et al.,
2007). The latter can influence $C A$, body size and perhaps performance variables. For example, among U-13 Flemish soccer players in the 3rd and 4th birth quarters had the same CA, $11.3 \pm 0.5$ years (Deprez et al., 2013). Studies regarding the RAE phenomenon clearly need to control for other factors and it is essential that all subjects are tested within a relatively narrow interval.

\section{Conclusions}

Evidence of the RAE was apparent in the Portuguese sample of U-15 soccer players; significantly greater for players born in the first half of the year (BQ1 and BQ2). The results highlighted the interaction of the RAE with predicted maturity status as potential developmental constraints among adolescent soccer players. The interaction between the RAE and maturity status yielded a large effect, specifically for body size. Players born in BQ1 and classified as early maturing were taller and heavier compared to peers born in BQ4 and classified late maturing. The interaction effect was moderate for running speed assessed as RSA. Overall, the results suggest a need for a constraints-based model with a developmental approach for youth soccer players. It can be argued perhaps that interacting constraints are often overlooked by coaches and sports organizations. Such an approach also provides a more comprehensive rationale to facilitate the understanding of the RAE in sports.

\section{Acknowledgements}

In memorium of Filipe Simões (SFRH/BD/78603/2011). Partially supported by Fundação para a Ciência e a Tecnologia [CIDAF: uid/dtp/04213/2019; JPD: SFRH/BD/101083/2014; DM: SFRH/BD/121441/2016; JVS: SFRH/BPD/100470/2014].

\section{References}

Bangsbo J, Norregaard L, Thorso F. Activity profile of competition soccer. Can J Sport Sci, 1991; 16(2): 110-116

Bell W. Body size and shape: A longitudinal investigation of active and sedentary boys during adolescence. J Sports Sci, 1993; 11: 127-38

Bishop D, Spencer M, Duffield R, Lawrence S. The validity of a repeated sprint ability test. J Sci Med Sport, 2001; 4(1): 19-29

Bucheit M. Repeated-sprint performance in team sport players: associations with measures of aerobic fitness, metabolic control and locomotor function. Int J Sports Med, 2012; 33: 230-239

Buchheit M, Mendez-Villanueva A, Simpson BM, Bourdon PC. Repeated-sprint sequences during youth soccer matches. Int J Sports Med, 2010; 31(10): 709-716

Carling C. Analysis of physical activity profiles when running with the ball in a professional soccer team. J Sports Sci, 2010; 28(3): 319-326 
Coelho-e-Silva MJ, Figueiredo AJ, Simões F, Seabra A, Natal A, Vaeyens R, Philippaerts R, Cumming SP, Malina RM. Discrimination of u-14 soccer players by level and position. Int J Sports Med, 2010; 31(11): 790-796

Deprez D, Coutts AJ, Fransen J, Deconinck F, Lenoir M, Vaeyens R, Philippaerts R. Relative age, biological maturation and anaerobic characteristics in elite youth soccer players. Int J Sports Med, 2013; 34(10): 897-903

Deprez D, Vaeyens R, Coutts AJ, Lenoir M, Philippaerts R. Relative age effect and Yo-Yo IR1 in youth soccer. Int J Sports Med, 2012; 33(12): 987-993

Deprez D, Valente-Dos-Santos J, Coelho-e-Silva MJ, Lenoir M, Philippaerts RM, Vaeyens R. Modeling developmental changes in yo-yo intermittent recovery test level 1 in elite pubertal soccer players. Int $J$ Sports Physiol Perform, 2014; 9(6): 1006-1012

Figueiredo AJ, Goncalves CE, Coelho-e-Silva MJ, Malina RM. Characteristics of youth soccer players who drop out, persist or move up. J Sports Sci, 2009a; 27(9): 883-891

Figueiredo AJ, Goncalves CE, Coelho-e-Silva MJ, Malina RM. Youth soccer players, 11-14 years: maturity, size, function, skill and goal orientation. Ann Hum Biol, 2009b; 36(1): 60-73

Fragoso I, Massuca LM, Ferreira J. Effect of birth month on physical fitness of soccer players (Under-15) according to biological maturity. Int J Sports Med, 2015; 36(1): 16-21

Froberg K, Andersen B, Lammert O. Maximal oxygen uptake and respiratory functions during puberty in boy groups of different physical activity. In Frenkl R, Szmodis I, editors. Children and Exercise: Pediatric Work Physiology XV. Budapest: National Institute for Health Promotion, 265-280; 1991

General Assembly of the World Medical Association. World Medical Association Declaration of Helsinki: ethical principles for medical research involving human subjects. J Am Coll Dent, 2014; 81(3): 14-18

Gil SM, Badiola A, Bidaurrazaga-Letona I, Zabala-Lili J, Gravina L, Santos-Concejero J, Lekue JA, Granados C. Relationship between the relative age effect and anthropometry, maturity and performance in young soccer players. J Sports Sci, 2014; 32(5): 479-486

Girard O, Mendez-Villanueva A, Bishop D. Repeated-sprint ability - part I: factors contributing to fatigue. Sports Med, 2011; 41: 673-694

Helsen W, Baker J, Micheils S, Schorer J, Van Winckel J, Williams MA. The relative age effect in European professional soccer: Did ten years of research make any difference? J Sports Sci, 2012; 30(15): 1665-1671

Helsen WF, Starkes JL, Van Winckel J. Effect of a change in selection year on success in male soccer players. Am J Hum Biol, 2000; 12(6): 729-735

Helsen WF, Starkes JL, van Winckel J. The influence of relative age on success and dropout in male soccer players. Am J Hum Biol, 1998; 10: 791-798

Hopkins WG, Marshall SW, Batterham AM, Hanin J. Progressive statistics for studies in sports medicine and exercise science. Med Sci Sports Exerc, 2009; 41(1): 3-13

Horn RR, Okumura M. It's time to eliminate the relative age effect in American soccer. Soccer J, 2011; 56(2): 38-40

Kaplan T. Examination of repeated sprinting ability and fatigue index of soccer players according to their positions. J Strength Cond Res, 2010; 24(6): 1495-1501

Koziel SM, Malina RM. Modified maturity offset prediction equations: validation in independent longitudinal samples of boys and girls. Sports Med, 2018; 48: 221-236

Lohman TG, Roche AF, Martorell R. Anthropometric standardization reference manual. Champaign, Illinois: Human Kinetics; 1988

Malina RM, Bouchard C, Bar-Or O. Growth, maturation, and physical activity. Champaign, Illinois: Human Kinetics; 2004

Malina RM, Choh AC, Czerwinski SA, Chumlea WC. Validation of Maturity Offset in the Fels Longitudinal Study. Pediatr Exerc Sci, 2016; 28(3): 439-455

Malina RM, Koziel SM. Validation of maturity offset in a longitudinal sample of Polish boys. J Sports Sci, 2014; 32(5): 424-437

Malina RM, Pena Reyes ME, Eisenmann JC, Horta L, Rodrigues J, Miller R. Height, mass and skeletal maturity of elite Portuguese soccer players aged 11-16 years. J Sports Sci, 2000; 18(9): 685-693 
Mirwald RL, Baxter-Jones, AD, Bailey DA, Beunen GP. An assessment of maturity from anthropometric measurements. Med Sci Sports Exerc, 2002; 34(4): 689-694

Moore SA, McKay HA, Macdonald H, Nettlefold L, Baxter-Jones ADG, Cameron N, Brasher PM. Enhancing a somatic maturity prediction model. Med Sci Sports Exerc, 2015; 47: 1755-1764

Mujika I, Spencer M, Santisteban J, Goiriena JJ, Bishop D. Age-related differences in repeated-sprint ability in highly trained youth football players. J Sports Sci, 2009; 27(14): 1581-1590

Muiller L, Gehmaier J, Gonaus C, Raschner C, Muiller E. Maturity Status Strongly Influences the Relative Age Effect in International Elite Under-9 Soccer. J Sports Sci Med, 2018; 17: 216-222

Philippaerts RM, Vaeyens R, Janssens M, Van Renterghem B, Matthys D, Craen R, Bourgois J, Vrijens J, Beunen G, Malina RM. The relationship between peak height velocity and physical performance in youth soccer players. J Sports Sci, 2006; 24: 221-230

Rodríguez-Fernández A, Sanchez-Sanchez J, Ramirez-Campillo R, Nakamura FY, Rodríguez-Marroyo JA, Villa-Vicente JG. Relationship between sprint ability, aerobic capacity, intermittent endurance and heart rate recovery in youth soccer players. J Strength Cond Res, 2017; doi: 10.1519/JSC.0000000000002193. [Epub ahead of print]

Rosnow RL, Rosenthal R. Computing contrasts, effect sizes, and counter nulls on other people's published data: General procedures for research consumers. Psychol Methods, 1996; 1: 331-340

Sanchez-Sanchez J, Sanchez M, Hernandez D, Ramirez-Campillo R, Martinez C, Nakamura FY. Fatigue in U12 Soccer-7 Players During Repeated One-Day Tournament Games - A Pilot Study. J Strength Cond Res, 2017; doi: 10.1519/JSC.0000000000002141. [Epub ahead of print]

Sherar LB, Baxter-Jones AD, Faulkner RA, Russell KW. Do physical maturity and birth date predict talent in male youth ice hockey players? J Sports Sci, 2007; 25(8): 879-886

Simmons C, Paull GC. Season-of-birth bias in association football. J Sports Sci, 2001; 19(9): 677-686

Valente-dos-Santos J, Coelho-e-Silva MJ, Martins RA, Figueiredo AJ, Cyrino ES, Sherar LB, Vaeyens R, Huijgen BC, Elferink-Gemser MT, Malina RM. Modelling developmental changes in repeated-sprint ability by chronological and skeletal ages in young soccer players. Int J Sports Med, 2012a; 33(10): 773780

Valente-dos-Santos J, Coelho-e-Silva MJ, Severino V, Duarte J, Martins RS, Figueiredo AJ, Seabra AT, Philippaerts RM, Cumming SP, Elferink-Gemser M, Malina, RM. Longitudinal study of repeated sprint performance in youth soccer players of contrasting skeletal maturity status. J Sports Sci Med, 2012b; 11(3): 371-379

Wattie N, Baker J. Happy birthday? Relative age and its influence on human development. Psychologist, 2013; 26: $110-113$

Wattie N, Schorer J, Baker J. The relative age effect in sport: a developmental systems model. Sports Med, 2015; 45(1): 83-94

\section{Corresponding author:}

\section{Manuel J Coelho-e-Silva}

Faculty of Sports Science and Physical Education, University of Coimbra, Coimbra, Portugal, Estádio Universitário de Coimbra, Pavilhão III, 3040-156 Coimbra.

Telephone number: +351964 809054

Fax: +351 239802779

E-mail: mjcesilva@hotmail.com 